\title{
Therapeutic Applications of Ethanol: A Review
}

\author{
Brendan Le Daré ${ }^{1,2}$, Thomas Gicquel ${ }^{1,2}$ \\ 1. Univ Rennes, INSERM, INRA, Institut NuMeCan (Nutrition, Metabolisms and Cancer) Rennes, France. \\ 2. Rennes University Hospital, Forensic Toxicology Laboratory, Rennes, France.
}

Received, July 31, 2019; Revised, September 17, 2019; Accepted, September 31, 2019; Published, October 3, 2019.

\begin{abstract}
Purpose: To review knowledge on therapeutic uses of ethanol and the latter's effectiveness and safety profiles in a range of indications. Methods: MEDLINE and PubMed databases were searched for relevant peer-reviewed papers published in English between 1888 and 2018 using the following search terms: ethanol, therapeutic, alcohol withdrawal syndrome, antiseptic, antidote, methanol, ethylene glycol, neurolysis, embolization, cyst, sclerosing agent, sclerotherapy, arteriovenous malformations, ablating agent. Studies providing information about association between alcohol and therapeutic indications, or mechanic explanation for the association were included for review. Results: According to the World Health Organization, approximately three millions deaths worldwide are attributable to alcohol consumption each year. However, the low-to-moderate consumption of ethanol has a number of beneficial effects (mainly on cardiovascular mortality and diabetes). Hence, ethanol has an unusual spectrum of effects that seems interesting for therapeutic purposes. Ethanol's risk-benefit ratio appears to be positive in some therapeutic indications such as antidote to methanol or ethylene glycol poisoning, neurolysis, alcohol withdrawal syndrome, or antiseptic. Conclusion: With the development of interventional radio technologies, and thus extremely precise access to anatomical structures, alcohol has been given new indications - particularly as an embolization, sclerosing or ablation agent. Moreover, constant progress in our knowledge of ethanol's pharmacodynamics might highlight other therapeutic indications for this compound in the future. Ethanol's low cost and wide availability make it a valuable therapeutic agent, compared with other reference treatments. Furthermore, ethanol has a long track record of safety and effectiveness in the indications mentioned above.
\end{abstract}

\section{INTRODUCTION}

On September 21 ${ }^{\text {st }}, 2018$, the World Health Organization (WHO) published its "Global Status Report on Alcohol and Health". The report provides an overview of alcohol consumption and harm worldwide. The WHO estimated that in 2016, approximately 3 million deaths (mainly in men) were attributable to alcohol consumption corresponding to one death every 10 seconds. Consequently, with a global population of nearly 7.36 billion people that year, alcohol consumption caused one in 20 deaths. Beside the deaths, alcohol consumption generated 132.6 million disabilityadjusted life years; this makes alcohol the third greatest risk for disease and disability. Deaths attributable to alcohol consumption were divided into three categories by the WHO: infectious disease, non-communicable disease, and injuries. In 2016, these categories respectively accounted for $12.9 \%, 28.7 \%$ and $58.4 \%$ of the deaths attributable to alcohol [1]. It is interesting to note that ethanol increases the risk of infectious diseases (such as HIV/AIDS, tuberculosis and lower respiratory tract infections) by impairing immune responses [2-4]. This effect is compounded by other factors; for example, alcohol consumption promotes unprotected sex and thus exposes users to sexually transmitted diseases. Chronic alcohol abuse is associated with poor treatment adherence and thus contributes to the development of resistance - particularly in HIV infections [4,5]. Furthermore, alcohol is a major known risk factor in different types of injury, such as road traffic injuries, drowning, burns, poisonings, and falls [6-8]. Alcohol also promotes violent attacks, homicides, and suicides [1]. Lastly, alcohol is associated with the development and/or progression of many non-communicable diseases, including cardiovascular disease, cancer, liver disease, and mental, behavioral and neurodevelopmental disorders. These diseases account for most of the deaths ascribed to alcohol $[9,10]$. This toxicity is directly linked to (i) ethanol's ability to distribute itself throughout all body fluids, and (ii) the toxic-generating metabolism of ethanol.

Corresponding Author: Brendan Le Daré Univ Rennes, INSERM, INRA, Institut NuMeCan (Nutrition, Metabolisms and Cancer) F-35000 Rennes, France. E-mail: brendan.le.dare@chu-rennes.fr 
Interestingly, low-to-moderate alcohol consumption is associated with beneficial health effects (summarized in Table 1). The "French paradox" is founded on this phenomenon, and several meta-analyses have evidenced an inverse correlation between low-to-moderate alcohol consumption (about to one to two units per day) and mortality from cardiovascular disease [11-13]. Similarly, a meta-analysis of data from 1,902,605 participants evidenced a peak risk reduction of developing type 2 diabetes for intakes between 10 to 14 grams of alcohol (corresponding to about a single standard drink or one units) per day in women and in non-Asian populations [14]. As was seen for the cardiovascular risk, the risk of developing type 2 diabetes became higher when consumption rose above 63 grams of alcohol per day. Some studies have suggested that the effect in these moderate consumers is due to the combination of a decrease in fasting insulin concentrations with an increase in the insulin sensitivity [15]. In 2018, a meta-analysis of data on 28 million people confirmed these results and showed a beneficial effect of low-to-moderate alcohol consumption on type 2 diabetes. However, the researchers concluded that overall mortality remains unchanged, given the increase in deaths due to other causes [16]. Recent studies have tended to show that moderate alcohol consumption has a neuroprotective action, including beneficial effects in Parkinson's disease, Alzheimer's disease, and dementia. Even though the underlying mechanisms have not been fully characterized, researchers suggest that ethanol has an antiinflammatory effect and increases neuroplasticity [17-20]. Furthermore, low-to-moderate ethanol consumption has also been linked to lower pain levels in and the delayed onset of Meniere's disease [21,22]. For several decades, several studies reported that ethanol (one to three units of alcohol per day) had beneficial effects on bone mineral density $[23,24]$. This is thought to be due to the higher endogenous estrogen levels induced by ethanol $[25,26]$. Lastly, given alcohol's influence on the immune system (and particularly its anti-inflammatory effects), some researchers have focused on the compound's effects on autoimmune diseases. Indeed, beneficial effects have been reported; it seems that the incidences of rheumatoid arthritis, systemic lupus erythematosus and thyroid disease (both hyperthyroidism and hypothyroidism) are inversely associated with low ethanol consumption (three to 30 units per week, depending on the study) [27-34]. The underlying mechanism has not yet been identified.

Table 1. The main beneficial effects attributable to low-to-moderate consumption of ethanol

\begin{tabular}{|c|c|c|}
\hline Beneficial effect & Mechanism & References \\
\hline $\begin{array}{l}\text { Decreased mortality from cardiovascular } \\
\text { diseases } \\
\text { (French paradox) }\end{array}$ & $\begin{array}{l}\text { Antioxidant effect } \\
\text { Increase in high density lipoprotein level } \\
\text { Reduction in low density lipoprotein level }\end{array}$ & [11-13] \\
\hline $\begin{array}{l}\text { Decrease in the risk of developing type } 2 \\
\text { diabetes }\end{array}$ & $\begin{array}{l}\text { Decrease in fasting insulin concentrations and } \\
\text { lower insulin sensitivity }\end{array}$ & {$[14,15]$} \\
\hline $\begin{array}{l}\text { Neuroprotective effect } \\
\text { (against Parkinson's disease, } \\
\text { Alzheimer's disease, and dementia) }\end{array}$ & $\begin{array}{l}\text { Anti-inflammatory effect and increased } \\
\text { neuroplasticity }\end{array}$ & {$[17-20]$} \\
\hline Osteoporosis & $\begin{array}{l}\text { Ethanol-induced high levels of endogenous } \\
\text { estrogens }\end{array}$ & {$[23-26]$} \\
\hline Antalgic effects & Central Nervous System depressant effect & {$[21]$} \\
\hline Delayed onset of Meniere's disease & Unknown & [22] \\
\hline $\begin{array}{l}\text { Autoimmune diseases } \\
\text { (Systemic lupus, hyperthyroidism, } \\
\text { hypothyroidism, rheumatoid arthritis) }\end{array}$ & Unknown & {$[27-34]$} \\
\hline
\end{tabular}


Just as ethanol has a spectrum of harmful and beneficial effects, the compound's risk-benefit ratio appears to be favorable in some indications making alcohol a valuable therapeutic.

In this review, MEDLINE and PubMed databases were searched for relevant papers published in English between 1888 and 2018 using the following search terms: ethanol, therapeutic, cyst, alcohol withdrawal syndrome, antiseptic, antidote, methanol, ethylene glycol, neurolysis, embolization, sclerosing agent, ablating agent, arteriovenous malformations, sclerotherapy. Studies providing information about association between alcohol and therapeutic indications, or mechanic explanation for the association were included for review.

\section{THERAPEUTIC USES OF ETHANOL}

Interestingly, scientists in the late 19th century regarded alcohol as a therapeutic agent $[35,36]$. Their knowledge of ethanol's metabolism and toxicity was summed up by Fermie in 1894 by the nuanced phrase "It can save as well as destroy". The use of alcohol was advocated empirically in indications of insomnia, fever, and cholera [36].

In the late $19^{\text {th }}$ century and early $20^{\text {th }}$ century, alcohol was listed in the British Pharmacopoeia (as spiritus vini gallici). The Lancet and the British Medical Journal respectively considered that "brandy is so universally regarded as superior to all other spirits from a medicinal point of view", [37] and " no other kind of brandy corresponds better to medical necessities than pure grape brandy " [38]. At that time, alcohol was used as a cardiac stimulant, an antipyretic, a nutritional aid, a sedative, an inhalation anesthetic, and in angina [39]. Thus, even prominent scientists, such as Pasteur, recommended the use of alcohol for health purposes (Figure 1).

In the 1920s, American physicians made great efforts to obtain the right to prescribe beer, alcohol, and other alcoholic beverages to their patients for medicinal purposes. However, the Prohibition brought in by the Eighteenth Amendment put an end to these efforts. [41].

As the pathophysiology of alcohol-related disorders became better understood and better alternatives were discovered, the therapeutic use of alcohol declined during the $20^{\text {th }}$ century. In 1949 , the main indication for alcohol was the prevention of delirium tremens [39]. Today, ethanol is still used in evidence-based medical practice in a number of indications (reviewed below, and summarized in Table 2).

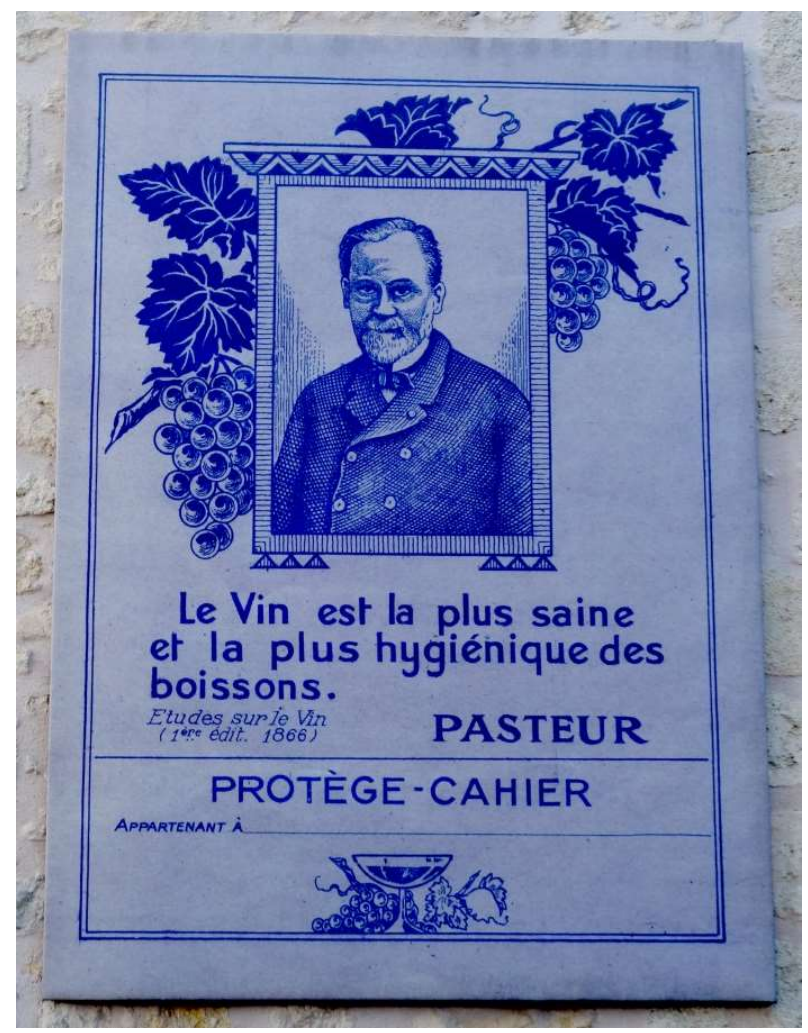

Figure 1. Promotional label of old wine brands entitled: «Le vin est la plus saine et la plus hygiénique des boissons » ("Wine is the healthiest and most hygienic drink"). Quotation from Pasteur's book "Etudes sur le vin" ("Studies on wine”) from 1866 [40]. 
Table 2. The main therapeutic indications of ethanol

\begin{tabular}{|c|c|c|}
\hline Indication & Mechanism & References \\
\hline \multirow[b]{2}{*}{ Antiseptic } & Denaturation of cytoplasmic and membrane proteins & \multirow[b]{2}{*}[42,43]{} \\
\hline & Inhibition of nucleic acid and protein synthesis & \\
\hline Alcohol withdrawal syndrome & $\begin{array}{l}\text { A gamma-aminobutyric acid agonist (sedation through } \\
\text { inhibition of the central nervous system) }\end{array}$ & [44-48] \\
\hline $\begin{array}{l}\text { Antidote for methanol or ethylene } \\
\text { glycol intoxication }\end{array}$ & $\begin{array}{l}\text { A competitive substrate for alcohol dehydrogenase (ADH), } \\
\text { blocking the toxic metabolism of methanol and ethylene } \\
\text { glycol }\end{array}$ & {$[49-52]$} \\
\hline Neurolysis & $\begin{array}{l}\text { Nonselective destruction of nervous tissue through the } \\
\text { precipitation of cell membrane proteins, lipid extraction, and } \\
\text { demyelination, leading to Wallerian degeneration }\end{array}$ & {$[53-61]$} \\
\hline Embolization & $\begin{array}{l}\text { Induction of thrombosis by denaturing blood proteins, } \\
\text { denuding the vascular wall of endothelial cells, precipitating } \\
\text { the latter's protoplasm, and segmentally fracturing the } \\
\text { vascular wall at the internal elastic lamina }\end{array}$ & {$[62-74]$} \\
\hline \multirow{2}{*}{ Sclerosing agent } & $\begin{array}{l}\text { Herniated disks } \\
\text { Ethanol desiccates the disk, resulting in a retraction of the } \\
\text { aqueous nucleus and thus a reduction in intradiscal pressure }\end{array}$ & \multirow{2}{*}[75-82]{} \\
\hline & $\begin{array}{l}\text { Sclerotherapy of nodules } \\
\text { Dehydration of epithelial cells and denaturation of cyst } \\
\text { proteins, leading to obliteration of the cyst through coagulant } \\
\text { necrosis, reactive fibrosis, and small vessel thrombosis }\end{array}$ & \\
\hline Ablating agent & $\begin{array}{l}\text { Necrosis of parts of the heart area exposed to ethanol, } \\
\text { abolishing the arrhythmic foci }\end{array}$ & [83-92] \\
\hline
\end{tabular}

\section{Antiseptic}

Today, the best-known use of ethanol in therapy is certainly its external use as a disinfectant antiseptic. Indeed, ethanol (along with isopropanol and n-propanol) is the alcohol most widely used as an antimicrobial disinfectant and antiseptic. Ethanol has a broad spectrum of action against vegetative bacteria, including mycobacteria (but not sporulating bacteria), viruses, and fungi [42]. Alcohol exerts its activity by denaturing membrane and cytoplasmic proteins, interfering with cell metabolism, and thus producing cell lysis. Unlike other antiseptics, ethanol's effectiveness is not correlated linearly with its concentration. The antimicrobial activity is optimal in the $60 \%$ to $90 \%$ range but falls off markedly below 50\% [42].

The medical indications in this field mainly concern skin antisepsis and hard surface disinfection. Given the absence of residual action after evaporation, ethanol is usually combined with other antiseptics (e.g. chlorhexidine and povidone iodine) [43].
Fungal resistance to alcohols by phenotypic modulation has been described for many years, although the data on bacterial and viral resistance are reassuring [42]. However, some recent studies have suggested an increase in bacterial resistance to alcohols in recent years; in particular, the Enterococcus faecium strains isolated in hospitals after 2010 show an isopropanol tolerance threshold 10 times greater than that measured for older strains [93].

\section{Alcohol withdrawal syndrome}

In addition to ethanol's external use, this alcohol is commonly used internally in various indications. In France, ampoules of absolute ethanol are marketed under the trade name CURETHYL ${ }^{\circledR}$ for acute adjunct therapy during alcohol withdrawal management. Depending on the type of withdrawal syndrome, several ampoules are administered a day (at decreasing doses) [44].

Despite this marketing authorization and the use of ethanol in alcohol withdrawal management, the effectiveness of this procedure is subject to 
debate in the literature $[45,46]$. Furthermore, inconsistent pharmacokinetics and a narrow therapeutic index mean that the routine use of this drug is not recommended by some researchers [45].

Hence, benzodiazepines are still considered to be the first-line treatment for alcohol withdrawal syndrome, due to their efficacy and safety profile [48]. In the event of resistance to benzodiazepines during the management of alcohol withdrawal, Dixit et al (2016) suggested a protocol using enteral ethanol. Fifty percent of the patient's estimated ethanol intake is administered as beer or vodka via a nasogastric tube every 4 to 6 hours for 24 hours, along with lorazepam. If the symptoms persisted, the ethanol dose was increased to $100 \%$ of the estimated daily intake. Treatment was continued for a minimum of three days, until the symptoms of alcohol withdrawal syndrome had disappeared, or for a maximum of seven days [47].

\section{Ethanol as an antidote}

Ethanol undergoes intense oxidative phase I metabolism by alcohol dehydrogenase (ADH) and cytochrome $\mathrm{P} 450$ 2E1, which gives rise to acetaldehyde. The latter is a powerful toxin, and has many harmful effects. Ultimately, acetaldehyde is metabolized to acetate and thus eliminated by acetaldehyde dehydrogenase [94].

In cases of methanol or ethylene glycol intoxication, ethanol can be used as a competitive $\mathrm{ADH}$ substrate in order to significantly reduce the production of the toxic metabolites of methanol (i.e. formaldehyde) and ethylene glycol (i.e. glycolic acid and oxalic acid). The treatment goal is to maintain an ethanol level of between 1 and 1.5 $\mathrm{g} / \mathrm{L}$ until the serum concentration of methanol or ethylene glycol has fallen to below $0.20 \mathrm{~g} / \mathrm{L}$ $[49,50]$.

Some researchers have compared the effectiveness of ethanol and fomepizole (the second reference treatment that act by inhibiting $\mathrm{ADH})$ in combating methanol poisoning. Although ethanol is associated with a higher incidence of complications and adverse effects, no differences in clinical effectiveness were found - suggesting that ethanol is still useful in this indication [51]. Rietjens et al (2014) compared the respective advantages and disadvantages of fomepizole and ethanol in the treatment of ethylene glycol and methanol poisoning. Although fomepizole is easier to handle, ethanol is still used as a first-line antidote in some medical centers due to its low cost, ready availability, and familiarity for physicians [52].

\section{Neurolysis}

Ethanol is also indicated in chemical neurolysis for analgesic purposes and in the treatment of spasticity [53]. The main analgesic indications are the destruction of scar neuroma, the treatment of cancer pain (such as neuropathic pain caused by neoplastic invasion or of paraneoplastic origin), the treatment of various viral pain manifestations (such as shingles and post-herpetic neuralgia), and treatment-refractory chronic pain and sympathetically mediated pain [54-57]. Ethanol (typically in the $50 \%-100 \%$ range) is injected locally into the medullary, perimedullary or peripheral target nerve with electrostimulation guidance [54,58].

Ethanol produces the nonselective destruction of nervous tissue through precipitation of cell membrane proteins, lipid compound extraction, demyelination, and Wallerian degeneration. Ethanol injection reportedly produces an initial burning sensation along the nerve's path, followed by numbness in the same areas. Adverse effects include dysesthesia, hyperesthesia, cardiac rhythm disturbance, hypotension, skin and non-targettissue necrosis, and central nervous system excitation. Furthermore, alcohol injections can also cause a disulfiram-like reaction if the patient is taking an $\mathrm{ADH}$ inhibitor [57]. In rare instances, celiac plexus neurolysis can result in paraplegia due to (i) diffusion of the neurolytic agent into arteries supplying the spinal cord, and (ii) the contraction of lumbar segmental arteries in response to ethanol and phenol [59].

Unfortunately, the effectiveness of chemical neurolysis has never been evaluated in a randomized, controlled trial. In 2001, Furlan et al. reviewed chemical neurolysis (using alcohol or phenol) for the treatment of neuropathic pain in a total of 66 patients [60]. The results were contrasting: $44 \%$ of the patients experienced meaningful pain relief, whereas $19 \%$ experienced non-meaningful relief. For the remaining 37\%, poor outcome reporting prevented any conclusions from being drawn. Interestingly, some researchers have compared the effectiveness of alcohol neurolysis with that of other treatments in certain indications. In the case of splanchnic nerve neurolysis, Koyyalangunta et al (2016) compared ethanol and phenol in terms of effectiveness, complications, and the duration of a beneficial effect; there were no differences between these two compounds, suggesting that the choice of neurolytic medication can be based on the clinician's judgement and product availability [61]. 


\section{Embolization}

Absolute ethanol has been used as a chemoembolization agent for many years, due to its thrombotic effect. Furthermore, technical progress in interventional radiology has enabled highly selective access to many anatomical areas [62]. Guidelines on ethanol chemoembolization (a technique mainly used in Japan, despite its offlabel status) were published in 2016 [63]. Ethanol induces thrombosis by denaturing blood proteins, denuding the vascular wall of endothelial cells, precipitating the latter's protoplasm, and segmentally fracturing the vascular wall at the internal elastic lamina [64]. A 5- to 30-minute balloon occlusion can be used to control the blood flow during the procedure [63]. Based on this observation, percutaneous alcohol injections have two main therapeutic indications: the treatment of arteriovenous malformations, and tumor embolization.

There are literature reports on the ethanol embolization of various arteriovenous malformations (in the kidneys, jaw, periorbital area, neck, ears and the hands), and posttraumatic or congenital fistulas, with good levels of efficacy and safety [62,65-69]. Although absolute (99\%) ethanol was used in most cases, more dilute (50$70 \%$ ) ethanol is required for the treatment of microfistulas [67]. In a retrospective study of complications in 175 ethanol embolization procedures (mainly in the limbs, pelvic cavity, and trunk), Do et al. reported an acceptable risk of adverse effects; there were 27 (15\%) minor complications (skin injury and transient peripheral nerve injury) and $5(3 \%)$ major complications (an infection, a case of acute renal failure, a permanent nerve injury in the arm, a brain infarct, and a case of focal bladder necrosis) [67].

In the field of oncology, ethanol embolization is used (alone or in combination with ethiodized oil or polyvinyl alcohol) to treat cases of hepatocellular carcinoma [70], renal angiomyolipoma, and carcinoma [71-73]. Alcohol causes cell dehydration, coagulation necrosis, intratumor arterial thrombosis, and thus tumor ischemia. However, the combination of percutaneous ethanol injections with chemoembolization in the treatment of liver metastases does not appear to prolong patient survival [74]. In a study of 83 cases of hepatobiliary cancer, Sofue et al. reported that right portal vein embolization prior to hepatic resection is safe and effective, and reduces the risk of postoperative liver failure [70]. In 1999, Kalman et al. reviewed 3225 cases of renal cell carcinoma embolization, and found a low level of evidence among all the publications. However, complete pre-operative renal artery embolization seems to facilitates the excision of large vein-invading tumors, and palliative embolization in nonoperable tumors with serious hemorrhage appears to have been successful in most cases [73]. Lastly, ethanol's properties are of value in the treatment of recurrent malignant thyroid cancers (e.g. papillary thyroid carcinoma) for which the risk of surgical complications is too high or when the patient refuses surgery [75].

\section{Ethanol as a sclerosing agent}

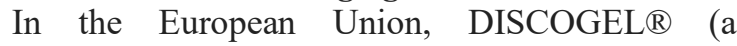
radiopaque gel of $96 \%$ ethanol and micronized tungsten) is marketed as a class III medical device for the treatment of certain types of herniated disk [76]. In 2018, Sayhan et al. reported that the gel provided significant, complication-free pain relief (relative to preoperative pain levels) in 33 patients with a herniated disk up to 12 months after the procedure, and was not associated with complications [76]. The device's effectiveness has been attributed to the ethanol's desiccant action, resulting in a retraction of the disk's aqueous nucleus and thus a reduction in the intradiscal pressure.

Ethanol remains the most commonly used compound for cyst sclerotherapy, due to its availability, low cost and good tolerance. The main indications are hepatic, renal and thyroid cysts [77,78]. After aspiration of the cyst content, a volume of ethanol corresponding to $50 \%$ of the aspirated cyst's volume is injected. Ethanol's sclerosing mechanism may be due to dehydration of the epithelial cell walls and the denaturation of cyst proteins. This leads to coagulant necrosis, reactive fibrosis, small vessel thrombosis, and thus obliteration of the cyst [78]. After the injection of ethanol into the cyst, the patient is turned in different directions so that the alcohol comes into contact with the whole cyst wall. After approximatively 20 minutes, the alcohol is removed by aspiration. The patient is usually followed up for three months. The sclerosis can be repeated - especially if the cyst is large.

The efficacy and safety data on percutaneous ethanol sclerotherapy are reassuring. In cases of hepatic cysts, Moorthy et al. showed that this procedure was as effective as laparoscopic unroofing, and was associated with a lower incidence of complications [79]. In cases of renal cysts, Akinci et al.'s report on 98 single-session sclerotherapies evidenced an average cyst reduction of $93 \%$ at the end of the first year. Furthermore, $17.5 \%$ of the cysts had completely 
disappeared, $90 \%$ of patients reported a reduction in flank pain, and $87.5 \%$ of the hypertensive patients became normotensive [80]. Lastly, ethanol sclerotherapy seems to be effective and safe in the treatment of benign cystic thyroid nodules, after the first use of percutaneous ethanol in this indication was reported by Edmonds et al. in 1987 [81]. In a prospective study of 15 patients with predominant cystic thyroid nodules, Jayesh et al. showed that injection of $95 \%$ ethanol into the cyst with ultrasound guidance was associated with complete disappearance of the cyst in four patients, and with a significant reduction $(\geq 50 \%$ of initial volume) in the cyst volume in nine patients. The two patients who failed to show a significant reduction in cyst volume had nodules $\geq 20 \mathrm{~mL}$. Even though no complications were attributable to ethanol injection during the study's three-months follow-up period, mild transient pain or a burning sensation at the injection site may be experienced following sclerotherapy [78]. In some cases of thyroid nodules, ethanol ablation has been coupled with radiofrequency ablation - thus increasing the procedure's effectiveness [82].

\section{Ethanol as an ablating agent in cardiology}

Although radiofrequency catheter ablation remains the primary treatment for cardiac arrhythmias, alcohol ablation of the coronary artery seems to be a valuable alternative when the first-line treatment fails [83]. The first septal branch ablation techniques in humans appeared in 1994, and were used to treat New York Heart Association Functional Classification stage III or IV obstructive hypertrophic cardiomyopathy under echocardiographic guidance [84]. The volumes of ethanol currently used (1-2 mL) are lower than those used for embolization, and are infused over 30 to 60 seconds to avoid atrioventricular block. A balloon catheter is also kept inflated for at least 5 minutes, in order to prolong contact with the alcohol $[85,86]$.

The main indications for alcohol found in the literature are ablation of ventricular tachycardia [87-89], ventricular fibrillation [90], and atrial fibrillation [91]. The success of these procedures are attributed to necrosis of the area of the heart area exposed to ethanol, and thus abolition of the arrhythmic foci. Accordingly, ethanol ablation is an excellent treatment option for arrhythmic foci located at deep myocardial sites, and those refractory to endocardial and epicardial ablation [83]. Although complications following ethanol ablations seem to be rare, some studies have reported a risk of atrioventricular block when the septal artery is targeted - requiring permanent pacemaker implantation in up to one third of patients [92].

\section{CONCLUSION}

Since ethanol's toxicity is closely related to its oxidative metabolism, the severity of intoxication is also closely correlated with the amount of alcohol consumed. Given that therapeutic applications of alcohol involve small amounts, the reported safety profile is good. Furthermore, the duration of exposure is relatively short, and so the chronic toxicity of ethanol reported by the WHO is not of relevance in these therapeutic settings. Ethanol's low cost and wide availability make it a valuable therapeutic agent, compared with other reference treatments. Furthermore, ethanol has a long track record of safety and effectiveness in the indications mentioned above. With the development of interventional radio technologies, and thus extremely precise access to anatomical structures, alcohol has been given new indications - particularly as an embolization, sclerosing or ablation agent. Moreover, constant progress in our knowledge of ethanol's pharmacodynamics might highlight other therapeutic indications for this compound in the future.

\section{ACKNOWLEDGMENTS}

The authors thank English language editing and review services supplied by Biotech communication SARL and Pontchaillou University Hospital (F-35000, Rennes, France).

\section{CONFLICT OF INTEREST}

The authors declare that there is no conflict of interest regarding the publication of this article.

\section{REFERENCES}

1. WHO | Global status report on alcohol and health $2018 . \quad$ WHO n.d. http://www.who.int/substance_abuse/publications/g lobal_alcohol_report/gsr_2018/en/ (accessed February 25, 2019).

2. Imtiaz S, Shield KD, Roerecke M, Samokhvalov AV, Lönnroth K, Rehm J. Alcohol consumption as a risk factor for tuberculosis: meta-analyses and burden of disease. European Respiratory Journal 2017;50:1700216. doi:10.1183/13993003.002162017.

3. Simou E, Britton J, Leonardi-Bee J. Alcohol and the risk of pneumonia: a systematic review and metaanalysis. BMJ Open 2018;8:e022344. doi:10.1136/bmjopen-2018-022344. 
4. Rehm J, Probst C, Shield KD, Shuper PA. Does alcohol use have a causal effect on HIV incidence and disease progression? A review of the literature and a modeling strategy for quantifying the effect. Population Health Metrics 2017;15. doi:10.1186/s12963-017-0121-9.

5. Hendershot CS, Stoner SA, Pantalone DW, Simoni JM. Alcohol Use and Antiretroviral Adherence: Review and Meta-Analysis: JAIDS Journal of Acquired Immune Deficiency Syndromes 2009;52:180-202. doi:10.1097/QAI.0b013e3181b18b6e.

6. Rivara FP, Koepsell TD, Jurkovich GJ, Gurney JG, Soderberg R. The effects of alcohol abuse on readmission for trauma. JAMA 1993;270:1962-4.

7. Haagsma JA, Graetz N, Bolliger I, Naghavi M, Higashi H, Mullany EC, et al. The global burden of injury: incidence, mortality, disability-adjusted life years and time trends from the Global Burden of Disease study 2013. Injury Prevention 2016;22:318. doi:10.1136/injuryprev-2015-041616.

8. Haddon W. Advances in the epidemiology of injuries as a basis for public policy. Public Health Rep 1980;95:411-21.

9. Hay SI, Abajobir AA, Abate KH, Abbafati C, Abbas $\mathrm{KM}$, Abd-Allah F, et al. Global, regional, and national disability-adjusted life-years (DALYs) for 333 diseases and injuries and healthy life expectancy (HALE) for 195 countries and territories, 19902016: a systematic analysis for the Global Burden of Disease Study 2016. The Lancet 2017;390:1260344. doi:10.1016/S0140-6736(17)32130-X.

10. Whiteford HA, Degenhardt L, Rehm J, Baxter AJ, Ferrari AJ, Erskine HE, et al. Global burden of disease attributable to mental and substance use disorders: findings from the Global Burden of Disease Study 2010. The Lancet 2013;382:1575-86. doi:10.1016/S0140-6736(13)61611-6.

11. Belleville J. The French paradox: possible involvement of ethanol in the protective effect against cardiovascular diseases. Nutrition 2002;18:173-7.

12. Albert CM, Manson JE, Cook NR, Ajani UA, Gaziano JM, Hennekens CH. Moderate alcohol consumption and the risk of sudden cardiac death among US male physicians. Circulation 1999;100:944-50. doi:10.1161/01.cir.100.9.944.

13. Ronksley PE, Brien SE, Turner BJ, Mukamal KJ, Ghali WA. Association of alcohol consumption with selected cardiovascular disease outcomes: a systematic review and meta-analysis. BMJ 2011;342:d671. doi:10.1136/bmj.d671.

14. Knott C, Bell S, Britton A. Alcohol Consumption and the Risk of Type 2 Diabetes: A Systematic Review and Dose-Response Meta-analysis of More Than 1.9 Million Individuals From 38 Observational Studies. Diabetes Care 2015;38:1804-12. doi:10.2337/dc15-0710.

15. Schrieks IC, Heil ALJ, Hendriks HFJ, Mukamal KJ, Beulens JWJ. The effect of alcohol consumption on insulin sensitivity and glycemic status: a systematic review and meta-analysis of intervention studies. Diabetes Care 2015;38:723-32. doi:10.2337/dc141556.

16. Griswold MG, Fullman N, Hawley C, Arian N, Zimsen SRM, Tymeson HD, et al. Alcohol use and burden for 195 countries and territories, 1990-2016: a systematic analysis for the Global Burden of Disease Study 2016. The Lancet 2018;392:1015-35. doi:10.1016/S0140-6736(18)31310-2.

17. Tizabi Y, Getachew B, Ferguson CL, Csoka AB, Thompson KM, Gomez-Paz A, et al. Low Vs. High Alcohol: Central Benefits Vs. Detriments. Neurotoxicity Research 2018. doi:10.1007/s12640017-9859-x.

18. Yasar S. Relation between alcohol consumption in midlife and dementia in late life. BMJ 2018:k3164. doi:10.1136/bmj.k3164.

19. Peters R, Peters J, Warner J, Beckett N, Bulpitt C. Alcohol, dementia and cognitive decline in the elderly: a systematic review. Age and Ageing 2008;37:505-12. doi:10.1093/ageing/afn095.

20. Paganini-Hill A, Kawas CH, Corrada MM. Lifestyle Factors and Dementia in the Oldest-old: The 90+ Study. Alzheimer Disease \& Associated Disorders 2016;30:21-6. doi:10.1097/WAD.0000000000000087.

21. Scott JR, Hassett AL, Schrepf AD, Brummett CM, Harris RE, Clauw DJ, et al. Moderate Alcohol Consumption Is Associated with Reduced Pain and Fibromyalgia Symptoms in Chronic Pain Patients. Pain Medicine 2018. doi:10.1093/pm/pny032.

22. Sánchez-Sellero I, San-Román-Rodríguez E, Santos-Pérez S, Rossi-Izquierdo M, Soto-Varela A. Alcohol consumption in Menière's disease patients. Nutritional Neuroscience 2018:1-7. doi:10.1080/1028415X.2018.1470372.

23. Holbrook TL, Barrett-Connor E. A prospective study of alcohol consumption and bone mineral density. BMJ 1993;306:1506-9. doi:10.1136/bmj.306.6891.1506.

24. Angus RM, Sambrook PN, Pocock NA, Eisman JA. Dietary intake and bone mineral density. Bone Miner 1988;4:265-77.

25. Felson DT, Zhang Y, Hannan MT, Kannel WB, Kiel DP. Alcohol intake and bone mineral density in elderly men and women. The Framingham Study. Am J Epidemiol 1995;142:485-92. doi:10.1093/oxfordjournals.aje.a117664.

26. Ganry O, Baudoin C, Fardellone P. Effect of alcohol intake on bone mineral density in elderly women: The EPIDOS Study. Epidémiologie de 1'Ostéoporose. Am J Epidemiol 2000;151:773-80. doi:10.1093/oxfordjournals.aje.a010277.

27. Di Giuseppe D, Alfredsson L, Bottai M, Askling J, Wolk A. Long term alcohol intake and risk of rheumatoid arthritis in women: a population based cohort study. BMJ 2012;345:e4230. doi:10.1136/bmj.e4230.

28. Jin Z, Xiang C, Cai Q, Wei X, He J. Alcohol consumption as a preventive factor for developing rheumatoid arthritis: a dose-response meta-analysis 
of prospective studies. Annals of the Rheumatic Diseases 2014;73:1962-7. doi:10.1136/annrheumdis-2013-203323.

29. Rajakulendran S, Gadsby K, Deighton C. Rheumatoid arthritis, alcohol, leflunomide and methotrexate. Can changes to the BSR guidelines for leflunomide and methotrexate on alcohol consumption be justified? Musculoskeletal Care 2008;6:233-46. doi:10.1002/msc. 135.

30. Jonsson I-M, Verdrengh M, Brisslert M, Lindblad S, Bokarewa M, Islander $\mathrm{U}$, et al. Ethanol prevents development of destructive arthritis. Proceedings of the National Academy of Sciences 2007;104:25863. doi:10.1073/pnas.0608620104.

31. Hardy CJ, Palmer BP, Muir KR, Sutton AJ, Powell RJ. Smoking history, alcohol consumption, and systemic lupus erythematosus: a case-control study. Ann Rheum Dis 1998;57:451-5. doi:10.1136/ard.57.8.451.

32. Nagata C, Fujita S, Iwata H, Kurosawa $Y$, Kobayashi $\mathrm{K}$, Kobayashi $\mathrm{M}$, et al. Systemic lupus erythematosus: a case-control epidemiologic study in Japan. Int $\mathrm{J}$ Dermatol 1995;34:333-7. doi:10.1111/j.1365-4362.1995.tb03614.x.

33. Carle A, Pedersen IB, Knudsen N, Perrild H, Ovesen L, Rasmussen LB, et al. Moderate alcohol consumption may protect against overt autoimmune hypothyroidism: a population-based case-control study. European Journal of Endocrinology 2012;167:483-90. doi:10.1530/EJE-12-0356.

34. Carlé A, Bülow Pedersen I, Knudsen N, Perrild H, Ovesen L, Rasmussen LB, et al. Graves' hyperthyroidism and moderate alcohol consumption: evidence for disease prevention. Clinical Endocrinology 2013;79:111-9. doi:10.1111/cen.12106.

35. Mellanby E. DISCUSSION ON THE VALUE OF ALCOHOL AS A THERAPEUTIC AGENT. Proc R Soc Med 1920;13:36-43.

36. Fermie A. Alcohol as a Therapeutic Agent. Ind Med Gaz 1894;29:199.

37. THE LANCET Special Analytical Commission ON BRANDY. The Lancet 1902;160:1502-18. doi:10.1016/S0140-6736(01)38315-0.

38. Reports and Analyses and Descriptions of New Inventions, in Medicine, Surgery, Dietetics, and the Allied Sciences. Br Med J 1888;2:885-6.

39. Guly H. Medicinal brandy. Resuscitation 2011;82:951-4. doi:10.1016/j.resuscitation.2011.03.005.

40. Pasteur L. Études sur le vin: Ses maladies, causes qui les provoquent, procédés nouveaux pour le conserver et le vieillir. Paris, imprimerie impériale; 1866.

41. Jacob M. Appel. "Physicians are not Bootleggers": The Short, Peculiar Life of the Medicinal Alcohol Movement. Bulletin of the History of Medicine 2008;82:355-86. doi:10.1353/bhm.0.0005.

42. McDonnell G, Russell AD. Antiseptics and disinfectants: activity, action, and resistance. Clin Microbiol Rev 1999;12:147-79.
43. Centre d'appui pour la prévention des infections associées aux soins. Utilisation des antiseptiques en établissement médico-social 2016.

44. VIDAL HOPTIMAL 2018. CURETHYL (éthanol), Monographie VIDAL 2018.

45. Hodges B, Mazur JE. Intravenous Ethanol for the Treatment of Alcohol Withdrawal Syndrome in Critically Ill Patients. Pharmacotherapy 2004;24:1578-85. doi:10.1592/phco.24.16.1578.50945.

46. Dillard R, Welch T, Abdul-Hamed S, Kesey J, Dissanaike S. Ethanol Infusion for Alcohol Withdrawal Prophylaxis Does Not Cause Intoxication. The Southwest Respiratory and Critical Care Chronicles 2016;4. doi:10.12746/swrcce2016.0416.214.

47. Dixit D, Endicott J, Burry L, Ramos L, Yeung SYA, Devabhakthuni S, et al. Management of Acute Alcohol Withdrawal Syndrome in Critically Ill Patients. Pharmacotherapy: The Journal of Human Pharmacology and Drug Therapy 2016;36:797-822. doi:10.1002/phar.1770.

48. Mirijello A, D’Angelo C, Ferrulli A, Vassallo G, Antonelli M, Caputo F, et al. Identification and Management of Alcohol Withdrawal Syndrome. Drugs 2015;75:353-65. doi:10.1007/s40265-0150358-1.

49. Jacobsen D, McMartin KE. Antidotes for methanol and ethylene glycol poisoning. J Toxicol Clin Toxicol 1997;35:127-43.

50. Beatty L, Green R, Magee K, Zed P. A systematic review of ethanol and fomepizole use in toxic alcohol ingestions. Emerg Med Int 2013;2013:638057. doi:10.1155/2013/638057.

51. Zakharov S, Pelclova D, Navratil T, Belacek J, Komarc M, Eddleston M, et al. Fomepizole versus ethanol in the treatment of acute methanol poisoning: Comparison of clinical effectiveness in a mass poisoning outbreak. Clinical Toxicology 2015;53:797-806. doi:10.3109/15563650.2015.1059946.

52. Rietjens SJ, de Lange DW, Meulenbelt J. Ethylene glycol or methanol intoxication: which antidote should be used, fomepizole or ethanol? Neth J Med 2014;72:73-9.

53. THERIAQUE 2018. ETHANOL AP-HP 96\% SOL INJ AMP n.d.

54. Loh T-H, Patel S, Mirchandani A, Eckmann M. Brachial Plexus Chemical Neurolysis with Ethanol for Cancer Pain. Case Reports in Medicine 2018;2018:1-3. doi:10.1155/2018/8628645.

55. Mahli A, Coskun D. Neurolysis for Treatment of Infraorbital Neuropathy. Case Reports in Medicine 2017;2017:1-4. doi:10.1155/2017/2389354.

56. Brock M, Frangakis C, Georgiades CS. CT-Guided, Percutaneous Ethanol Sympatholysis for Primary Hyperhidrosis. CardioVascular and Interventional Radiology 2018;41:477-82. doi:10.1007/s00270017-1806-y.

57. Department of Physical Medicine and Rehabilitation, Jefferson Medical College, Thomas 
Jefferson University, Philadelphia, PA 19107, USA, Zhou L, Craig J, Parekh N. Current Concepts of Neurolysis and Clinical Applications. Journal of The Analgesics 2015;2:16-22. doi:10.14205/23110317.2014.02.02.1.

58. Viel E, Pelissier J, Pellas F, Boulay C, Eledjam J. Les traitements locaux de la spasticité: Blocs périphériques des membres pour alcoolisation ou phénolisation neurolytique. Neurochirurgie 2003;49:256-62. doi:NCHIR-05-2003-49-2-3C20028-3770-101019-ART14.

59. Johnson ME, Sill JC, Brown DL, Halsey TJ, Uhl CB. The effect of the neurolytic agent ethanol on cytoplasmic calcium in arterial smooth muscle and endothelium. Reg Anesth 1996;21:6-13.

60. Furlan AD, Lui PW, Mailis A. Chemical sympathectomy for neuropathic pain: does it work? Case report and systematic literature review. Clin J Pain 2001;17:327-36.

61. Koyyalagunta D, Engle MP, Yu J, Feng L, Novy DM. The Effectiveness of Alcohol Versus Phenol Based Splanchnic Nerve Neurolysis for the Treatment of Intra-Abdominal Cancer Pain. Pain Physician 2016;19:281-92.

62. Yakes WF, Luethke JM, Parker SH, Stavros AT, Rak KM, Hopper KD, et al. Ethanol embolization of vascular malformations. RadioGraphics 1990;10:787-96.

doi:10.1148/radiographics.10.5.2217971.

63. Japanese Society of Interventional Radiology. Guidelines for Absolute Ethanol for Use in Vascular Embolization, 2016 edition. 2016.

64. Prasetyono TOH, Kreshanti P. Efficacy of intralesional alcohol injection as alternative and/or complementary treatment of vascular malformations: A systematic review. Journal of Plastic, Reconstructive \& Aesthetic Surgery 2010;63:1071-9. doi:10.1016/j.bjps.2009.04.020.

65. Su L, Jia R-B, Wang D-M, Lv M-M, Fan X. Absolute Ethanol Embolization of Arteriovenous Malformations in the Periorbital Region. CardioVascular and Interventional Radiology 2015;38:632-41. doi:10.1007/s00270-014-0993-Z.

66. Fan XD, Su LX, Zheng JW, Zheng LZ, Zhang ZY. Ethanol Embolization of Arteriovenous Malformations of the Mandible. American Journal of Neuroradiology 2009;30:1178-83. doi:10.3174/ajnr.A1539.

67. Do YS, Yakes WF, Shin SW, Lee B-B, Kim D-I, Liu WC, et al. Ethanol Embolization of Arteriovenous Malformations: Interim Results. Radiology 2005;235:674-82. doi:10.1148/radiol.2352040449.

68. Su L, Wang D, Han Y, Wang Z, Zheng L, Fan X. Absolute Ethanol Embolization of Infiltratingdiffuse Extracranial Arteriovenous Malformations in the Head and Neck. European Journal of Vascular and Endovascular Surgery 2015;50:114-21. doi:10.1016/j.ejvs.2015.02.020.

69. Zheng LZ, Fan XD, Zheng JW, Su LX. Ethanol Embolization of Auricular Arteriovenous Malformations: Preliminary Results of 17 Cases.
American Journal of Neuroradiology 2009;30:167984. doi:10.3174/ajnr.A1687.

70. Sofue K, Arai Y, Shimada K, Takeuchi Y, Kobayashi T, Satake M, et al. Right portal vein embolization with absolute ethanol in major hepatic resection for hepatobiliary malignancy. British Journal of Surgery 2014;101:1122-8. doi:10.1002/bjs.9541.

71. Rimon U, Duvdevani M, Garniek A, Golan G, Bensaid P, Ramon J, et al. Ethanol and Polyvinyl Alcohol Mixture for Transcatheter Embolization of Renal Angiomyolipoma. American Journal of Roentgenology 2006;187:762-8. doi:10.2214/AJR.05.0629.

72. Sawada Y, Shimohira M, Hashizume T, Sobue R, Mori S, Nakagawa M, et al. Transcatheter Arterial Embolization for Renal Angiomyolipoma Using a Micro-balloon Catheter and a Mixture of Ethanol and Lipiodol. CardioVascular and Interventional Radiology 2017;40:1933-9. doi:10.1007/s00270017-1731-0.

73. Kalman D, Varenhorst E. The role of arterial embolization in renal cell carcinoma. Scand J Urol Nephrol 1999;33:162-70.

74. Riemsma RP, Bala MM, Wolff R, Kleijnen J. Percutaneous ethanol injection for liver metastases. Cochrane Database of Systematic Reviews 2013. doi:10.1002/14651858.CD008717.pub2.

75. Jeong SY, Baek JH, Choi YJ, Lee JH. Ethanol and thermal ablation for malignant thyroid tumours. International Journal of Hyperthermia 2017:1-8. doi:10.1080/02656736.2017.1361048.

76. Sayhan H, Beyaz SG, Ülgen AM, Yuce MF, Tomak Y. Long-term Clinical Effects of DiscoGel for Cervical Disc Herniation. Pain Physician 2018;21:E71-8.

77. Cheng D, Amin P, Van Ha T. Percutaneous Sclerotherapy of Cystic Lesions. Seminars in Interventional Radiology 2012;29:295-300. doi:10.1055/s-0032-1330063.

78. Jayesh S, Mehta P, Cherian M, Ilayaraja V, Gupta P, Venkatesh K. Efficacy and safety of USG-guided ethanol sclerotherapy in cystic thyroid nodules. Indian Journal of Radiology and Imaging 2009;19:199. doi:10.4103/0971-3026.54879.

79. Moorthy K, Mihssin N, Houghton PW. The management of simple hepatic cysts: sclerotherapy or laparoscopic fenestration. Ann R Coll Surg Engl 2001;83:409-14.

80. Akinci D, Akhan O, Ozmen M, Gumus B, Ozkan O, Karcaaltincaba M, et al. Long-term results of singlesession percutaneous drainage and ethanol sclerotherapy in simple renal cysts. European Journal of Radiology 2005;54:298-302. doi:10.1016/j.ejrad.2004.07.008.

81. Edmonds CJ, Tellez M. Treatment of thyroid cysts by aspiration and injection of sclerosant. Br Med $\mathrm{J}$ (Clin Res Ed) 1987;295:529. doi:10.1136/bmj.295.6597.529.

82. Park HS, Baek JH, Choi YJ, Lee JH. Innovative Techniques for Image-Guided Ablation of Benign 
Thyroid Nodules: Combined Ethanol and Radiofrequency Ablation. Korean Journal of Radiology doi:10.3348/kjr.2017.18.3.461.

83. Subramanian A. Alcohol Ablation for Cardiac Arrhythmias: Is it Time to Drown the Arrhythmias? Indian Pacing Electrophysiol J 2012;12:136-7. doi:10.1016/s0972-6292(16)30520-4.

84. Sigwart U. Non-surgical myocardial reduction for hypertrophic obstructive cardiomyopathy. Lancet (London, England) 1995;346:211-4. doi:10.1016/s0140-6736(95)91267-3.

85. Kitamura M, Kubota Y, Takano H, Takayama M. Alcohol septal ablation with septal myocardial isolation using the double-balloon method for refractory hypertrophic obstructive cardiomyopathy. European Heart Journal 2014;35:241-241. doi:10.1093/eurheartj/eht321.

86. Hagège AA, Desnos M. New trends in treatment of hypertrophic cardiomyopathy. Archives of Cardiovascular Diseases 2009;102:441-7. doi:10.1016/j.acvd.2009.03.008.

87. Kreidieh B, Rodríguez-Mañero M, A. Schurmann P, Ibarra-Cortez SH, Dave AS, Valderrábano M. Retrograde Coronary Venous Ethanol Infusion for Ablation of Refractory Ventricular Tachycardia. Circulation: Arrhythmia and Electrophysiology 2016;9. doi:10.1161/CIRCEP.116.004352.

88. Sacher F, Sobieszczyk P, Tedrow U, Eisenhauer AC, Field ME, Selwyn A, et al. Transcoronary ethanol ventricular tachycardia ablation in the modern electrophysiology era. Heart Rhythm 2008;5:62-8. doi:10.1016/j.hrthm.2007.09.012.

89. Brugada P, de Swart H, Smeets JL, Bär FW, Wellens HJ. Termination of tachycardias by interrupting blood flow to the arrhythmogenic area. Am J Cardiol 1988;62:387-92. doi:10.1016/00029149(88)90964-2.

90. Duncan E, Schilling RJ. Intracoronary ethanol ablation: A novel technique for ablation of ventricular fibrillation. Heart Rhythm 2010;7:11314. doi:10.1016/j.hrthm.2010.04.012.

91. Valderrábano M, Morales PF, Rodríguez-Mañero M, Lloves C, Schurmann PA, Dave AS. The Human Left Atrial Venous Circulation as a Vascular Route for Atrial Pharmacological Therapies. JACC: Clinical Electrophysiology 2017;3:1020-32. doi:10.1016/j.jacep.2017.02.022.

92. Tokuda M, Sobieszczyk P, Eisenhauer AC, Kojodjojo P, Inada K, Koplan BA, et al. Transcoronary Ethanol Ablation for Recurrent Ventricular Tachycardia After Failed Catheter Ablation: An Update. Circulation: Arrhythmia and Electrophysiology doi:10.1161/CIRCEP.111.966283.

93. Pidot SJ, Gao W, Buultjens AH, Monk IR, Guerillot $\mathrm{R}$, Carter GP, et al. Increasing tolerance of hospital Enterococcus faecium to handwash alcohols. Science Translational Medicine 2018;10:eaar6115. doi:10.1126/scitranslmed.aar6115.

94. Cederbaum AI. Alcohol Metabolism. Clinics in Liver Disease 2012;16:667-85. doi:10.1016/j.cld.2012.08.002. 